\title{
Product Value Chain in a Tertiary Institution: The Need for MCDM
}

\author{
Famous O. Igbinovia, Jiri Krupka \\ Institute of System Engineering and Informatics, \\ Faculty of Public Administration, University of Pardubice, \\ Studentská 84, 53210 Pardubice, Czech Republic \\ famousigbinovia@yahoo.co.uk,jiri.krupka@upce.cz
}

\begin{abstract}
Value chain examination of tertiary education institutions is centered on the dynamics of inter-connection within the education sector, most especially the way in which tertiary education providers such as universities, polytechnics, institutes and the likes are universally integrated, this entails conventional systems of economic, social analysis and much more. This research work is centered on the study of Edo State Institute of Technology and Management (ESITM) as a tertiary education provider, it is embarked upon in order to determine the institutes competitive advantage in the market place. It is hoped that this research would reveal the strengths and potential threats of the institute. The authors believe that this analysis would inform strategic planners and managers of the institute on the way forward to consolidate its position in the industry. Stakeholders of the institute are advised by the authors on the need of embarking on Multiple Criteria Decision Making (MCDM) in its policy making process, as this will make the institute focus on policies for improving access to education and training not only for middle manpower at ESITM, but equally be able to build degree holders workforce demand for services such as Research and Development (R\&D), design etc.
\end{abstract}

Keywords-product; value chain; competitive advantage; multiple criteria decision making; tertiary institution; edo state institute of technology and management

\section{INTRODUCTION}

In today's knowledge operated economy, the function of tertiary education turns out to be very important in the general socio-economic advancement of any society. No nation can advance in this competitive world without learning and wisdom. Thus, the significance of tertiary education cannot be beneath spotlight [1]. Tertiary education has undergone remarkable modification in recent past. The perception of business focus of education and the students as customers or end users is getting stronger. With the universal trend of tertiary education, the demand and supply balance are changing. Tertiary institutions of higher learning are under immense pressure to provide value to the learner customers and other stakeholders. One of the greatest challenge faced by tertiary education institutions today is to accommodate costs and at the same time to augment productivity [2]. This analysis sought to investigate the developments at ESITM, which came into existence with a bill signed into law on 19th December, 2002. After the establishment of the tertiary institution in 2002, the name was modified from Edo State Polytechnic to Edo State Institute of Technology and Management (ESITM). The change in the name of the institute was to meet the National Board for Technical Education (NBTE) requirements ratio of $70 \%$ - 30\% technology to management courses [3].

Every tertiary institution has competitive forces which controls its existence in the market place. Five competitive forces have been singled out in every tertiary education establishment. A study of such competitive forces is essential in divulging tertiary education provider's foundational attractiveness, revealing the basic drivers of its profitability giving an understanding on how profitability will progress in the near future given the feasible changes in technology, communication channels, appearance of substitutes and competitors. It is also asserted that the attractiveness of a tertiary education institution is furthermore guaranteed by the same five fundamental forces [4] - [5].

The other sections of this research paper are organized as follows. Section 2 talks about the concept of multiple criteria decision making and value chain. Section 3 discusses the value chain analysis methodology for ESITM. Section 4 deals with the analytical design of the value chain created by ESITM. Section 5 analyzes the competitive advantage of ESITM base on SWOT analysis. Section 6 suggests the need for MCDM in ESITM in order to improve the quality of product. Finally, Section 7 concludes this research paper.

\section{The CONCEPT OF MUltiple CRITERIA DeCision MAKING AND VALUE CHAIN}

MCDM or MCDA are well-known shortened form for multiple criteria decision making and multiple criteria decision analysis. MCDM deals with structuring and solving decision and planning issues that has to deal with multiple criteria. The purpose of such is to support decision makers facing such problems. Typically, there does not exist a unique optimal solution for such problems and it is necessary to use decision maker's preferences to differentiate between solutions [6]. MCDM, is a valuable tool that can be applied to many complex 
decisions. It is most applicable to solving problems that are characterized as a choice among alternatives. It has all the characteristics of a useful decision support tool: It helps to focus on what is important, logical and consistent, and it is really easy to use. When used for group decision making like in a tertiary education environment, MCDM helps tertiary education planners and managers to discuss about their decision opportunity (that is the issue to be solved) in a way that allows decision makers to consider the values that each participant in the decision process view as important. It also provides a unique ability for decision makers to consider and discuss about complex trade-offs among alternative solutions. To a large extent, it enables people to think, re-think, query, adjust, decide, rethink some more, test, adjust, and finally decide on a particular issue [7]. It is regarded as an extension of decision theory that entails any decision with multiple objectives. A methodology for appraising alternatives on individuals, with frequently conflicting criteria, and merging them into one all-inclusive appraisal. MCDM is considered as a sub-discipline of operations research that in a clear and detailed manner assesses multiple conflicting criteria in decision making, both in everyday life and professional settings or environment. A number of approaches and methods, many of which can be implemented by specialized decision-making software, have been developed for their practical usage in range of disciplines, varying from education, politics, business, environment, energy etc [8] - [14]. Fig. 1, presents a hierarchical structure of MCDM Methods.

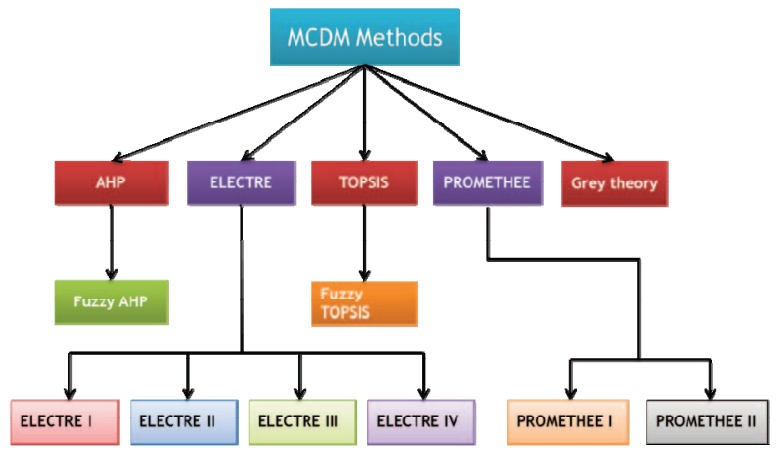

Fig. 1. Hierarchical structure of MCDM Methods [15].

The value chain idea was at first suggested by the author in [4], who put forward the study of the value creation process in a web of companies. The use of the terminology "chain" indicates emphasis on vertical relationships between buyers and suppliers and the movement of goods or services from producers to end-users. An industry value chain is including of suppliers providing the necessary input to a company; once a company has created a product, the created product passes through the value chain of distributors (which in the same likewise manner have their own value chains), until these products finally gets to the end-users. All the parts of these chains are included thereof in the value system and the innovation lies in taking into consideration the creation of value as a sequential process of specific sets of establishments. Presently, the emergence of globalization and the growth of global value chains have decided the development of the idea of value creation. It is no longer regarded as a linear sequence of financial added values but it is seen more broadly as a process including other economic players. For instance, the value-constellation and the value-grid models, the former focuses not on the company or the industry, but rather on the system creating value itself, which is consisting of suppliers, business partners, allies and end-users, all working together to co-produce value. Whereas the latter model involves a chain that has been extended both horizontally, vertically and diagonally in order to develop strategies that will bring about competitive advantage [16] - [18]. The shared-value has to do with the creation of economic value in a manner that equally creates value for the society, by addressing societal needs and challenges. While sustainable-value links the issues of global sustainability to the creation of shareholder value by firms [18] - [20].

Value chain study of a university, polytechnic, institute etc, is the careful examination of the value chain of such education provider in order to discover how much and at which stage or point value is added to its services, and how it can be increased to augment the institutions product differentiation or competitive advantage. In order to appreciate the competitive advantage of ESITM, by utilizing the value chain investigation hypothetical structure. The industry value chain has been elaborate as comprising the value creating campaign within a tertiary education provider environment such as course development right from one end to the delivery of course offerings and associated services to the student or learner. Valid research has showed the utility of value chain investigation to assist tertiary educational institutions decide the type of competitive advantage to employ and how to prosecute it. Two constituents of the value system have been recognized, that is, the education industry value chain and the tertiary institution's internal value chain [5], [21]. An educational value chain framework is shown in Fig. 2.

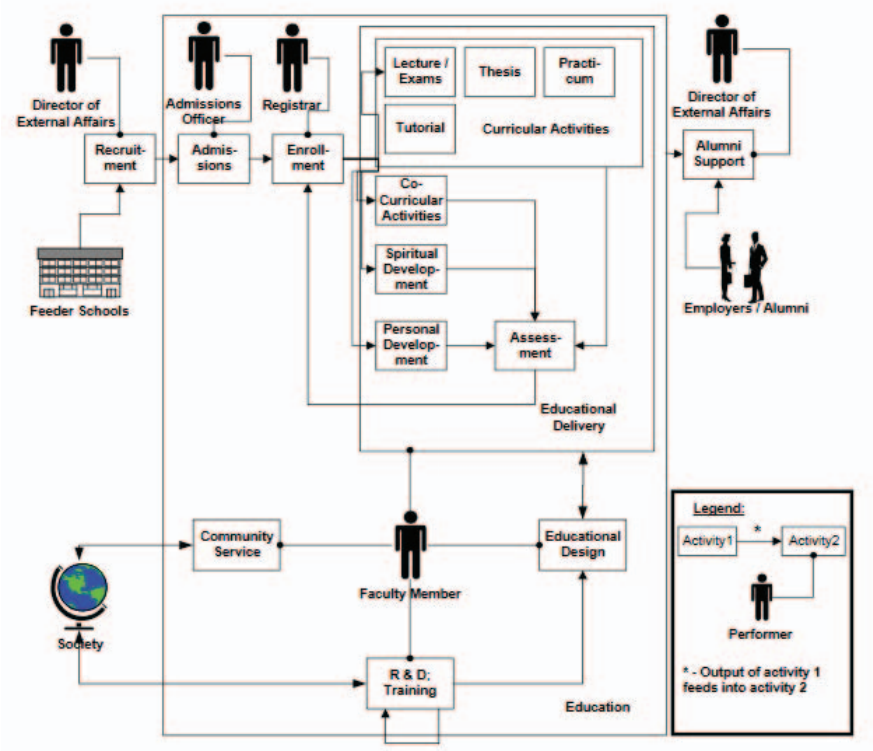

Fig. 2. Education Value Chain Framework [22].

For value to be added to its end products, institutions of tertiary education should look at adjusting their curriculum with a long-term view of the coming changes to high-skill 
occupations, especially with respect to problem identification and the management of uncertainty in highly automated work conditions. Changes to how existing courses are taught could make a significant difference. Technological courses could emphasize more open-ended problems approach rather than problems with a single correct answer approach, where students learn underlying ideas by utilizing these approach to real life applications. Also, technical courses should include problems where the students learn to include aesthetic, social, and financial concerns to technical ones. Furthermore, tertiary institutions managers should disseminate information among prospective and current students about occupations with the largest gains of employment and higher wage premiums, this will enable students to know what to expect after completion of studies [23]. The right policy decision on which choice to make by tertiary education managers and planners lies greatly on the adoption of MCDM by institutions of higher learning.

\section{Methodology of the Value Chain Analysis of ESITM}

The internal value chain of ESITM consists of all physical and technological easily distinguishable campaign inside the institute that attached value to the learners' experience. The key to examining and understanding value chain is to appreciate the various campaign inside the institute that produces competitive advantage for the institution, and then managing these campaigns better than other tertiary education institutions of higher learning within Nigeria, Africa and the world at large. Two groups of campaign is recommended: First, is the primary campaign straightforwardly involved in building and conveyance of the service, and second is the support campaigns which feed into the primary campaign and into each other. Support campaign included, human resources administration, technology growth not straightforwardly involved in the making of the end product, that is the learner, but have the potential to increase successfulness and efficiency. Hence, value chain study of ESITM is a way of investigating the internal operations and identifying which campaign is best provided by others entrants in the education industry [4].

\section{ANALyticAl DESIGN OF THE VALUE CHAIN CREATED BY ESITM}

The analytical design of the value chain created by ESITM is a qualitative study utilizing a study of the institutes document and relevant literature search as the main sources of data. The key campaigns by different sections and units of ESITM have been pointed out utilizing the institute's strategic plan document. The responsibilities of each departmental unit were equally recognized for their value creating campaigns to the entire institute. The institute's strategic plan of action is utilized to point out the vision and mission of the institute, its strengths and weaknesses and how it seeks to overcome threats from her competitors and entrants to the industry. These have been assessed by utilizing value chain investigation to find out the institute's competitive advantage in the tertiary education industry.

\section{A. Vision}

The vision of ESITM is to deal with the following issues [3]:

1. The unfavourable admission criteria for Edo state indigenes in Nigeria into polytechnics and universities.

2. Produce required manpower for industrial development.

3. Produce graduates who are self-reliant.

\section{B. Mission}

The mission of the institute are as follows [3]:

1. To provide training and research, particularly in technological sciences.

2. To arrange conferences, seminars and to provide higher education in the field of learning specified in 1. Above.

3. To disseminate scientific and technological knowledge among users especially scientist and researchers.

\section{Competitive Advantage OF ESITM BaSE ON SWOT ANALYSIS}

The Strength, Weakness, Opportunity, and Threat (SWOT) analysis of organizations like tertiary education institutions is a powerful tool that, with a little understanding, can help to discover the opportunities that can be utilized in an organization, such as ESITM to good advantage. And by uncomprehending the weaknesses of such higher education provider, it becomes easier to oversee and do away with threats that would or else catch the institute by surprise. Therefore, by using the SWOT framework to analyze ESITM as an organization and its competitors, a strategy is then created that helps to differentiate the institute from its competitors, so that ESITM can be a successful competitor in the global education industry.

\section{A. Strengths of ESITM}

ESITM for now is the only Edo state higher education institution of learning that specializes in the provision of middle manpower in the country, which makes the institute occupy a prime position as a higher education provider in Nigeria.

1. The management of ESITM is planning partnership with some tertiary institution of higher learning both in Nigeria and Abroad.

2. ESITM is a recognized brand in the industry.

3. ESITM produces its own self-contained instructional learning materials under the guidance of NBTE.

4. ESITM strongly has faith in women empowerment.

5. ESITM has print modules that can be utilized in her parttime programmes, even if organised in the isolated parts of the country.

6. ESITM benefits from the assistance of highly qualified staff.

7. ESITM has a Quality Assurance Unit which monitors the standard of various services contributed or rendered by staffers of the institute. 
8. ESITM has experience in running part-time programmes.

9. ESITM has a wide geographical coverage that cut across political boundaries of Nigeria, due to the centre geographical location of Edo state in Nigeria.

\section{B. Opportunities for ESITM to Exploit:}

1. ESITM has the opportunity for international expansion.

2. There is a school of business at the institute, whose business acumen and programmes can be utilized to introduce business ethics in the management of ESITM for greater efficiency and profitability.

3. ESITM has a wide student base, complemented by opening ESITM programmes to the entire world through e-platform;

4. ESITM has the opportunity for expanding her programmes on offer.

5. ESITM has increasing opportunity for economic security;

6. Senior management staff of the institute are committed to quality assurance.

7. ESITM has a past record of middle manpower development, with emphasis on technological development in the country with both state and federal government support.

8. ESITM is blessed with highly qualified personnel, both academic and non-academic staff, although at present they are inadequate.

9. Equally, the institute has diverse programmes and course offerings with more unexploited markets in the industry.

10. As more players come into the market through the opening of more tertiary institutions of higher learning, ESITM have to seek competitive advantage more urgent than before.

11. ESITM has customised learning resources of high quality;

12. ESITM is situated in a state and country where the population is hungry for quality education and also the populace values education.

13. The partnership with other institutions of higher learning provides the institute opportunities to learn from other well established tertiary institutions.

14. ESITM can run parallel programmes by day or night, this is achieved by investing fund to light up every nook and cranny of the institute, most especially for night classes.

\section{Weaknesses to the Opportunities of ESITM:}

The opportunities that ESITM benefit from are however, prevented by threats. Key among these threats are including of:

1. Poor funding base for ESITM.

2. ESITM lacks adequate student financial support by Edo state and federal government of Nigeria

3. There is poor internal communication among staffers of ESITM.

4. The turnover by staffers of the institute is inadequate.

5. There is usually delays in launching new programmes by ESITM.

6. There is generally no steady resource base for ESITM.
7. There is technological lag at the institute, such as no Local Area Network (LAN) and wide Area Network (WAN) at the location of ESITM;

\section{Threats to the Opportunities of ESITM :}

The weaknesses of ESITM have been further aggravated by threats in the environment which the institute has to be proactive about or work hard to overcome. The enumerated challenges listed below have to be overcome by ESITM in order to remain competitive in the tertiary education industry. These are including of:

1.The wrong idea about ESITM being an institution for middle manpower production only, instead of seeing it as an institution for producing both middle manpower certificate and degree awarding institution with regards to the institutes provision of standard tertiary education both at home and abroad.

2. There are departmental units that carry out the same functions in ESITM, this leads to duplication of duties and increases costs for the institute. The same applies to the institutes staff structure or organogram, thereby leading to the issue of bureaucracy in ESITM. The rationalisation of ESITM structures will go a long way in cost savings enabling the institute to remain competitive utilizing a low-cost model.

3. The same parallel programmes being run by other traditional tertiary education institutions of higher learning in the country;

4. ESITM has in short supply highly qualified academic and non-academic staff.

5. There is inadequate access of user to computer learning equipment's at ESITM.

6. ESITM does not have its own printing press, this issue does slow down and increase the cost of learning resources and module materials production.

7. Lack of creativity on the part of stakeholders of ESITM in responding to threats and reduce weaknesses being observed at the institute.

8. Intense competition from state, national and international tertiary educational institutions;

9. ESITM failure to capitalise on the combine running of lower national diploma, higher national diploma and degree programmes to aid comfort, such as work and family friendly environment, customization, higher standard of learning and lower cost of education to potential students.

10. Global proliferation of tertiary education.

11. Poor decisions or policies such as tuition fee paying arrangements for students by the management of ESITM.

12. Absence of/or weak business strategies such as market appraisal of students/learners demands on a continuous basis.

13. Failure of the management of ESITM to observe and justify staff level in reaction to the transformation in the number of students. This in certain instances supporting small staff levels for very high student numbers, thereby having low output and very little influence on the students, since 
lecturers/student percentage requests that lecturers should do more work and thus cannot have the time to give the students or learners their personal best.

14. ESITM unfavourable marketing publicity.

15. ESITM has no pension scheme for academic and nonacademic staff.

\section{THE NEED FOR MCDM IN ESITM TO IMPROVE THE QUALITY OF PRODUCT}

The functionality of MCDM is very high in educational organizations as it is utilized to solve complex issues. MCDM is used in all real-life applications such as educational policy specification and so on. The performance of educational organization like ESITM can be developed for better solution which can be obtained by utilizing MCDM. Taking ESITM for instance as a tertiary education provider, the collections of relevant information is done at the institute, to provide better solution for a problem. The relevant information will be helpful in making decision with regards to complex problem which may occurs at ESITM [15]. The flow diagram of a Multi criteria decision making analysis system is shown in Fig. 3. This can be modified for use by the institute.

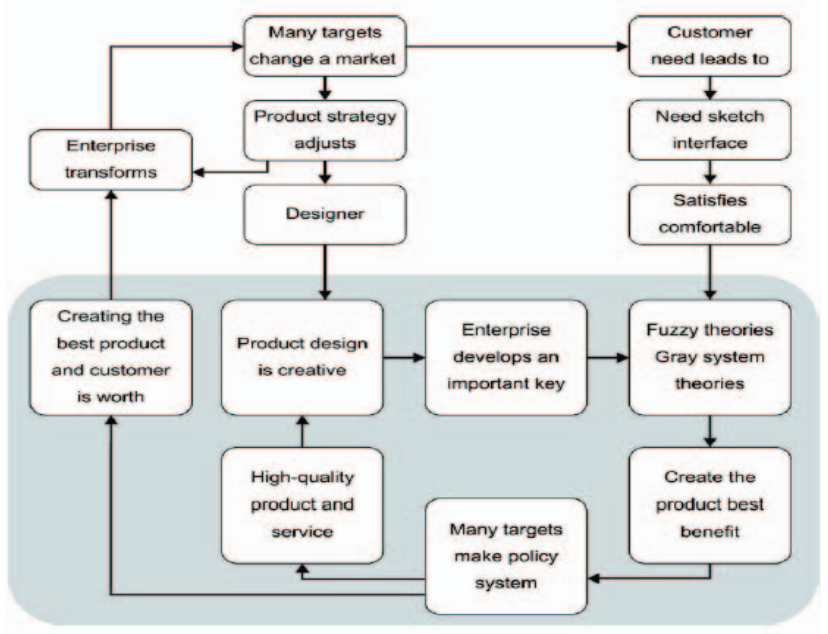

Fig. 3. Flow diagram of the MCDM analysis system [24]

MCDM will provide decision-makers in ESITM with the ability to look into the future, and to make the best possible decision based on past and present information and future predictions, this will be the true goal of an integrated decisionmaking system in the institute. In the case of sustainable development of ESITM, the goal for using MCDM will be to predict in advance the risk and vulnerability of students and staff populations infrastructure to hazards, both natural and man-made. This requires that data from the institute be transformed into knowledge, and the consequences of information use, as well as decision-making and participatory processes, be analyzed carefully. It will generally require to analyze the quantitative and qualitative data for educational institution application. MCDM will help to customize correct information at ESITM, where a student as a customer can get enough information regarding for instance educational loans. Visualization can be used to attract both student and staff users to often get accessed to information [15].

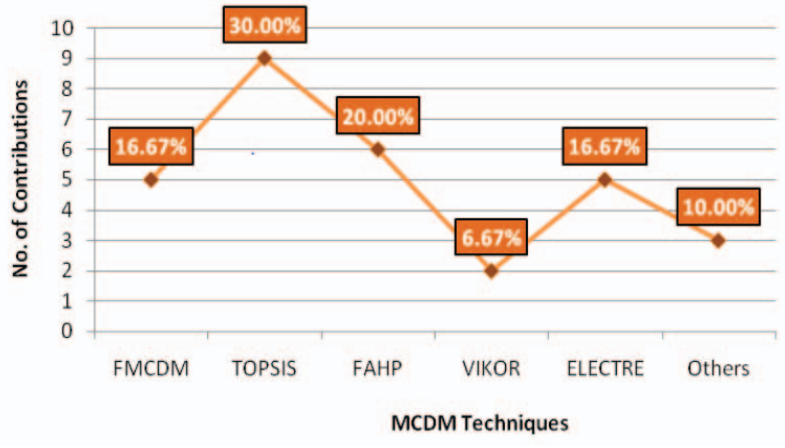

Fig. 4. MCDM methods and its contributions [15].

The contribution of the various MCDM methods or techniques is shown in Fig. 4, illustrating that TOPSIS method have had the highest numer of contribution so far, that is to say that TOPSIS method have been applied mostly in many applications as compared to other methods. ESITM can be advised to use TOPSIS method as this is the most popular technique. MCDM can be applied for information delivery in ESITM. loads of information's are obtained for various users like the student customers, stakeholders like government and management teams of ESITM etc. so it is essential to deliver the correct information to the end-users in the way they want, each end-users might have their own perception of information to be delivered to them, so in the institute various needs of end-users can be obtained by having many interviews from different end-users, making them to fill certain applications and questionnaire where it is possible to be able to capture the needs of each individual type of end-users, by this way the need of information delivery in ESITM can be improved to provide a better performance to both staff and students by customizing its information. For each user, information and content varies. Finding the best information end-user among students and staffers of ESITM and delivering the right information and in both end-user preferred channel must be delivered. The level of information equally varies where student and staff users need different information and the level of security varies too. Uncertainty issues in ESITM can be solved by using MCDM to provide the right information to the appropriate right user and at the right time in the institute [15]. A value chain model like the one presented in Fig. 5, for tertiary education can be practicable at ESITM by utilizing MCDM.

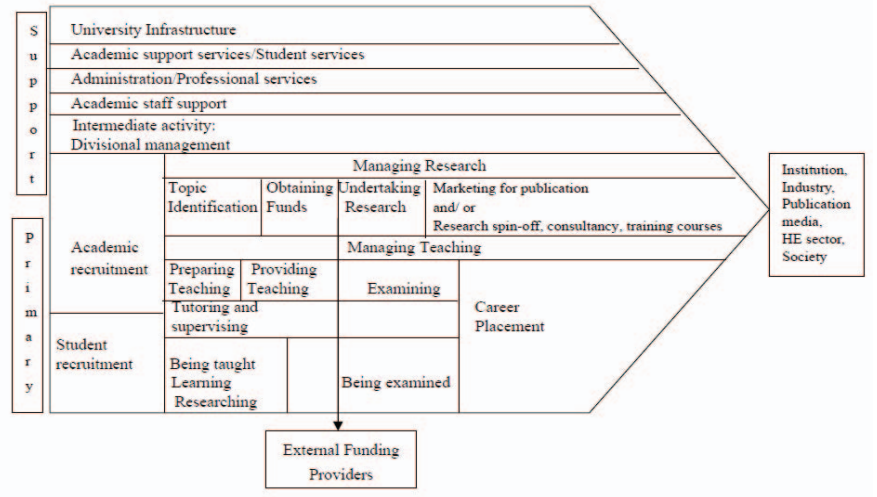

Fig. 5. Value Chain Model for Tertiary Education System [25]. 


\section{CONCLUSION}

A consistent approach to the utilization of value chain framework would enable a fast track identification of negative forces and threats from both national and international competitors of ESITM and the implementation of pro-active action by the strategic managers of the tertiary educational institution in order to preserve ESITM's superior position in the tertiary education industry. A value chain analysis for ESITM has been done in this paper, which showed its competitive advantage in the industry. An MCDM is needed for the institute, in order for these advantages to be taken care of.

The tertiary education industry is a multi-criteria domain. MCDM is applied to domains in which one need to evaluate more alternatives and multiple criteria and from that select the best alternative. This new perspective of utilizing MCDM in ESITM is believing will be of great significance for policy making in the tertiary education institution. Stakeholders of ESITM renewed attention in order to strengthen the institute should geared seriously towards adopting MCDM in their strategic plan, there is need for them to understand tertiary education in its full scope and consider the many services included in the value chain. MCDM will offer ESITM a more complete picture of tertiary education institution demand, probe deeper into its current position in the industry, and consequently produce new perspectives for adjusting current policy. If ESITM policy focuses only on improving access to education and training for middle manpower requirement but ignores degree workforce demand for services such as R\&D and design, it risks not realizing the full potential of innovation as a driver of productivity gains and economic growth and as a mitigating factor of wage disparities for endusers or product. Therefore, future research will be using MCDM for the innovative product value chain of ESITM to promote excellent product design for the institute.

\section{ACKNOWLEDGMENT}

This article was supported by the project No. SGS 2017 019 of the Ministry of Education, Youth and Sports of CR with title 'Models Synthesis and Analysis for Implementation Support of Smart Cities and Regions Concept' at the Faculty of Economics and Administration, University of Pardubice.

\section{REFERENCES}

[1] U. Makkar, E. O. Gabriel, and S. Tripathi, "Value Chain for Higher Education Sector-Case Studies of India and Tanzania," Journal of Services Research, 2008.

[2] R. Rathee, and P. Rajain, "Service value chain models in higher education. International Journal of Emerging Research in Management \&Technology,” 2013. ISSN, 2278-9359. Volume-2, Issue-7,

[3] ESITM, "Edo State Institute of Technology and Management Portal, Usen." [Online] Available from; http://www.esitmusen.edu.ng
[4] M. E. Porter, The Competitive Advantage: Creating and Sustaining Superior Performance. New York: Free Press, 1985.

[5] D. I. Ignatius, "Application of the value chain analysis framework to enhance understanding of competitive advantage at an Open and Distance Learning (ODL) Institution," Global Advanced Research Journal of Educational Research and Review. ISSN: 2315-5132, vol. 2, no.3 pp. 060-069, Mar. 2013.

[6] M. Majumder, Impact of Urbanization on Water Shortage in Face of Climatic Aberrations, Springer Briefs in Water Science and Technology, 2015.

[7] Multi-Criteria Decision Analysis, [Online]. Available from: https://www.ncsu.edu

[8] R. L. Keeney, H. Raiffa, Decisions with Multiple Objectives: Preferences and Value Trade-Offs. Cambridge University Press, Cambridge, UK,

[9] V. Belton, T. J. Stewart, 'Multiple Criteria Decision Analysis: An Integrated Approach," Kluwer Academic Publishers, Massachusetts, 2002 .

[10] European Medicines Agency. Benefit-risk methodology project. Update on work package 5: effects table pilot (phase I). 2015. [Online]. Available from: http://www.ema.europa.eu

[11] P. Thokala, N. Devlin, K.Marsh, R. Baltussen, M. Boysen, Z. Kalo, and M. Ijzerman, "Multiple criteria decision analysis for health care decision making - an introduction: report 1 of the ISPOR MCDA Emerging Good Practices Task Force,"Value in health, vol. 19, no. 1, pp. 1-13.

[12] H. R. Weistroffer, C. H. Smith, and S. C. Narula, "Multiple criteria decision support software", Ch 24 in: Figueira, J., Greco, S., and Ehrgott, M., eds, Multiple Criteria Decision Analysis: State of the Art Surveys Series, Springer: New York, 2005.

[13] P. McGinley, TERTIARY "Decision analysis software survey", OR/MS Today, 39.

[14] K. Angeliki, C. Elias, F. A. Paris, P. Polycarpos, "Multicriteria analysis for the selection of the most appropriate energy crops: the case of Cyprus".. International Journal of Sustainable Energy.

[15] M. Aruldoss, T. M. Lakshmi, V. P. Venkatesan, A survey on multi criteria decision making methods and its applications. American Journal of Information Systems. vol. 1, no. 1, pp. 31-43.

[16] R. Normann, R. Ramírez, "From value chain to value constellation: designing interactive strategy," Harv. Bus. Rev. 71, 1993, pp. 65-77.

[17] K. F. Pil, M. Holweg, "Evolving from value chain to value grid. MIT Sloan Manage. Rev. 47, 2006, pp. 72-80.

[18] F. F. Fagioli, L. Rocchi, L. Paolotti, R. Słowiński, and A. Boggia, "From the farm to the agri-food system: A multiple criteria framework to evaluate extended multi-functional value," Ecological Indicators, 79, 2017, pp. 91-102.

[19] M. E. Porter, M. R. Kramer, Creating shared value. Harv. Bus. Rev. 89. 2011.

[20] S. L. Hart, M. B. Milstein, Creating sustainable value. Acad. Manag. Exec. 17, 2003, pp. 56-67.

[21] BusinessDictionary.com, "Value Chain Analysis," [Online] Available from; http://www.businessdictionary.com

[22] R. Sison, and C. Z. Pablo, "Value Chain Framework and Support System for Higher Education, Proceedings of the Philippine Computing Science Congress, 2000, pp.1-6.

[23] W. S. Katie, V. D. Walter, and A, C. Gina, "Innovation and manufacturing labor: a value-chain perspective," Center for Technology Innovation at Brookings. 2015.

[24] C. S. Liao, "Using the MCDM of the Innovative Product Value Chain to Promote New Product Design. The East Asian Journal of Business Management, vol. 4, no. 3, 2014, pp. 27-37.

[25] A. K. Hutaibat, "Value Chain for Strategic ManagementAccounting in Higher Education," International Journal of Business and Management, vol. 6 , no. 11,2011 , pp. 206-218. 